Arteterapia. Papeles de arteterapia y educación para inclusión social ISSN-e 1988-8309

https://dx.doi.org/10.5209/arte.62565

\title{
Trabajando con la parte sana. Arteterapia en una mujer adulta con anorexia nerviosa crónica
}

\author{
Maria Soutullo Casanueva ${ }^{1}$
}

Recibido: 29 noviembre de 2018 / Aceptado: 17 abril de 2019

Resumen. Estudio de caso de una mujer anoréxica, que a través de la arteterapia fue capaz de redescubrir su parte sana, tras treinta años de enfermedad, dentro de un espacio seguro y de acompañamiento. A través de la arteterapia se pudo redescubrir la parte sana de la paciente y trabajar con ella, teniendo siempre bien presente esa imagen, ese dibujo, ese testigo mudo (Henzell,1997) que en ocasiones se convirtió en objeto transicional para entender aquello que estaba sucediendo en sesión.

La presencia de esa obra, facilitó la relación con el propio self de la paciente y con la terapeuta. Gracias al proceso creativo se pudo trabajar a través de los materiales esa relación que tenía con la comida, dentro de un espacio de contención.

El objetivo de este trabajo es mostrar como la arteterapia ayudó a tomar consciencia de la enfermedad y facilitó el proceso, para que tras varias décadas de enfermedad, la paciente pudiera comenzar a disfrutar de la vida, asumiendo sus limitaciones y circunstancias actuales.

Palabras clave: Arteterapia; trastornos de conducta alimentaria (TCA); anorexia; teoría de apego; objeto transicional.

\section{[en] Working with the healthy part. art therapy to an adult woman with chronic anorexia nervosa}

\begin{abstract}
Case study of an anorexic woman who was able to rediscover her healthy part after thirty years of illness, by means of art therapy, in a secure and accompanied space.

Art therapy enabled the connection between the patient and her healthy part, as well as the patient's ability to work with it, keeping in mind the image, drawing, or silent witness (Henzell, 1997) that sometimes became a transitional object to understand what happens during the session.

The presence of the artwork facilitated the patient's relationship with herself and with the therapist. The creative process allowed the patient to work with food related materials, within a containment space.

The goal of this work is to show how art therapy helped to become aware of the disease and facilitated the process, after several decades of illness; the patient could begin to enjoy life, assuming her limitations and current circumstances.

Keywords: Art therapy; eating disorders; anorexia; attachment theory; transitional object.
\end{abstract}

Sumario. 1. Introducción. 2. Los trastornos de la conducta alimentaria y su relación familiar. 3. Características de las personas con trastorno de conducta alimentaria ante el proceso de creación. 4. La obra como objeto transicional en el tratamiento de la anorexia. 5. Objetivo. 6. Pregunta de investigación. 7. Desarrollo de caso. 8. Conclusiones. 9. Bibliografía.

Cómo citar: Soutullo Casanueva, M. Trabajando con la parte sana. Arteterapia en una mujer adulta con anorexia nerviosa crónica, en Arteterapia. Papeles de arteterapia y educación para inclusión social $14,2019,39-54$.

1 Licenciada en Bellas Artes. Máster en Arteterapia. Psicoterapia por el arte y formación psicosocial. Universidad Pompeu Fabra de Barcelona.

E-mail: mariasoutullo@hotmail.com 


\section{Introducción}

El trastorno de la conducta alimentaria puede definirse como la manera que la persona afectada encuentra para enfrentarse a sus sentimientos y emociones negativas, a sus deficiencias y miedos. Este trastorno no se manifiesta en una persona emocionalmente sana y con una vida plena (Calvo, 2002).

En las últimas décadas, los trastornos de la conducta alimentaria (TCA), especialmente la anorexia y la bulimia, se han convertido en una plaga, afectando tanto a hombres como a mujeres. Aunque hace unos años la mayoría de las personas enfermas eran adolescentes y mujeres muy jóvenes, actualmente el rango de edad se ha ampliado, encontrando casos en preadolescentes, así como en mujeres que han superado los cuarenta años. Los factores que pueden influir en la aparición de la anorexia son muy numerosos, desde los genéticos, los biológicos y psicológicos hasta los socioculturales y familiares.

Algunos estudios destacan la influencia negativa de ciertos agentes socio-culturales, como la idealización mediática de cuerpos estilizados y artificiales, así como la presión que ejerce la sociedad sobre el estereotipo de la "mujer perfecta". Consecuencia de una sociedad de la abundancia manipulada por el consumo desmedido. Aunque es cierto que no todos los enfermos con este tipo de trastorno son mujeres, cierto es que la sociedad aún sigue reflejando el esquema freudiano del - deseo de ser mirada - y el voyerismo masculino - el deseo de ver - que se nos ha propuesto a lo largo de siglos de historia y que, del mismo modo, ha retomado la fotografía de moda, la cual poco a poco también está arrastrando al hombre hacia sus garras.

La anorexia nerviosa es un trastorno del comportamiento alimentario caracterizado por una pérdida significativa de peso debido al deseo voluntario de adelgazar. En ella se produce una distorsión de la imagen corporal y la persona se ve obesa independientemente del peso que tenga. Para conseguir adelgazar se disminuye o evita el consumo de alimentos, se provocan vómitos, se realiza ejercicio físico excesivo y se usan laxantes.

La edad de inicio del trastorno suele coincidir con el comienzo de la pubertad. La malnutrición produce graves alteraciones en la persona, dando lugar a todo tipo de síntomas y trastornos; entre ellos, amenorrea en mujeres y pérdida de interés y potencia sexual en hombres.

\section{Los trastornos de la conducta alimentaria y su relación familiar}

En el contexto familiar, resulta necesario precisar el papel que juega la madre en relación con el desarrollo y mantenimiento de conductas alimentarias desadaptadas y de la insatisfacción corporal, características presentes en dichos trastornos.

El alimento es el vehículo a través del cual recibimos la nutrición afectiva que proviene de la persona que nos cuida. Desde el principio de nuestra vida, el alimento material se trenza con el afectivo de tal modo que, si falta este último, se puede llegar a morir. La madre filtra a su hija, junto con la comida, su angustia, su impaciencia, su exigencia o su placer. A medida que el bebé crece y se desarrolla, sus necesidades van cambiando, poco a poco va probando su independencia, la evidencia de este hecho es cuando es capaz de arrastrarse, luego de caminar y finalmente cuando comienza a explorar el mundo (Eichenbaum y Orbach, 1983). Este hecho solo se puede 
lograr si la madre puede proporcionar un vínculo seguro, en donde el niño pueda experimentar con seguridad, siendo capaz de soportar el fracaso por parte de la madre (Winnicott, 1971). El niño necesita ser nutrido y alimentado, pero es importante que sea capaz de soportar un cierto grado de frustración para su buen desarrollo.

Toda madre imagina a su hija según sus deseos, pero tendrá que aceptar que será diferente. Toda niña fantasea con una madre poderosa que, sin embargo, la decepcionará porque es un ser humano, con defectos. La menor tendrá que resolver el conflicto entre estar apegada a su madre y querer ser como ella y rechazarla porque desea ser distinta. Algo que puede expresarse en darse atracones o rechazar el alimento porque este viene de la madre y desea separarse de ella. La hija tiene que resolver un dilema: ¿cómo convertirse en una mujer con deseos propios y desprenderse de la madre? Comer demasiado o no comer nada puede ser un intento de buscar una solución somática a una tensión interna. Entonces aparecen síntomas (inapetencia, atracones, compulsiones, obesidad, anorexia o bulimia) que pueden ser un intento de restaurar un interior dañado.

Los conflictos en torno a la comida son una forma de expresar el "hambre de amor" (Menéndez, 2013) que una mujer tiene hacia sí misma. Cuando una mujer adulta tiene una relación conflictiva con la comida, ello puede ser causado por una sensación que no fue resuelta en la infancia de forma adecuada en relación a su madre, que es el primer amor de todos los humanos.

La solución adictiva, decíamos, es para ellas la salida menos arriesgada en el plano afectivo, ya que sustituye el alimento afectivo por la comida, eludiendo así el compromiso que implica el reconocimiento de la necesidad, mantiene las emociones escindidas supliéndolas por las sensaciones; permite recrear la ilusión del control mágico omnipotente del objeto sin tener que soportar su ausencia, y recrea un paraíso oral en dónde queda negada la sexualidad. El objeto fetiche, en este caso la comida, se erige así como un talismán que reniega la separación y la diferencia sexual pretendiendo colmar el hambre afectivo a través de la ingesta alimentaria (Tejedor, 2002).

La escisión que padecen por la precariedad del desarrollo yoico, obliga a manipular la ingesta como a ese objeto, ora bueno, ora malo, que se acaricia, anhela, ansia o se desecha, teme, desprecia, descrito por Winnicott en la alternativa emocional suscitada por los objetos transicionales.

Este conjunto de dificultades hace que interiormente detrás de su arrogancia vivan acosadas por el temor a caer en su abismo depresivo o entregarse al desprecio e indiferencia de los seres que les rodean. Su adicción les protege así del vacío y de la posibilidad de ser rechazadas si enseñan su hambre de objetos.

\section{Caracteristicas de las personas con trastorno de conducta alimentaria ante el proceso de creación}

En general, los rasgos habituales de personas creadoras y las características de las personas con TCA son prácticamente opuestos. El trabajo creativo implica una serie de procesos psicológicos y recursos personales, como la flexibilidad, capacidad de asumir riesgos, tolerancia a la ambigüedad y a la incertidumbre, apertura a la experiencia, actitud crítica, capacidad de reflexión y de cuestionarse a sí mismo, disposición al cambio, búsqueda de nuevos discursos, etc. Como bien define Omenat 
(2006) "la creación implica un atravesamiento de límites, una transgresión que provoca ansiedad y a la vez placer. Placer por esa experiencia de liberación que supone lo nuevo, angustia por ese estremecimiento que provoca el caos, un cierto vértigo, un cierto vacío" (p.7).

En contraposición, las personas con TCA presentan dificultad para la expresión emocional, preocupación por la imagen y estética, miedo a ser juzgadas, conductas perfeccionistas, necesidad de agradar a los demás y controlar la situación, elevado nivel de autoexigencia y autocrítica, insatisfacción personal y ansiedad, desconfianza interpersonal y dificultades para la socialización. Esos rasgos personales y el inevitable miedo al lienzo blanco son susceptibles de ser elaborados a través del trabajo en arteterapia, ya que la autoevaluación y análisis del proceso creativo permite que las pacientes puedan llegar a identificar y resignificar sus propias conductas a través de la experiencia. Uno de los retos es poder llegar a crear, enfrentándose con ello al bloqueo del impulso creativo. De manera que trabajar en torno a las dificultades de la creación, es trabajar en torno a las propias dificultades o potencialidades (Winnicott, 1971).

Al mismo tiempo, la producción artística aporta a la persona una reorganización interna desde la salud mental, una autodeterminación simbolizada de forma visible a través de su obra. La expresión plástica implica para el creador una negociación con los materiales, una cierta plasticidad, mediante la cual lograr la construcción de un nuevo objeto.

En palabras de Klein (2006), "la materia no es un mediador, sino un interlocutor que tiene su carácter, que se defiende, que exige" (p. 13), por lo que el resultado final no muestra únicamente las emociones o conceptos que el autor pretendía expresar, sino que mantiene la huella del trabajo acontecido durante la negociación con dichos materiales.

El encuadre arteterapéutico favorece un trabajo simbólico y metafórico en el que el creador debe ponerse a prueba, cuestionarse a sí mismo, tomar decisiones, converger ideas, errar, frustrarse, innovar, sorprenderse, asumir riesgos, experimentar, superarse y reflexionar.

Para las pacientes en tratamiento por TCA el proceso de creación resulta un trabajo complicado, dada la poca seguridad que tienen en sí mismas y en sus habilidades, así como su necesidad de control y el miedo a lo desconocido. Como apunta López Fernández-Cao (2006), "la función primera del arteterapia será llevar a la persona a un estado de apertura y confianza en sí y en el espacio terapéutico, hacia la flexibilidad y la tolerancia hacia sí misma y hacia los demás, hacia la capacidad de arriesgarse" (p. 31). Así, la persona será capaz de situarse en un espacio de pérdida de lo conocido y al mismo tiempo de disponibilidad hacia lo nuevo.

Para ello, en las sesiones de arteterapia se ofrece a las pacientes un espacio en el que el diagnóstico clínico pierde importancia, lo que les obliga a reconocerse como personas completas, con las capacidades y limitaciones propias de cualquier individuo. En la revisión de la literatura sobre arteterapia y TCA que realiza Gilroy (2012), se mencionan las conclusiones de Waller (1994), quien explica que, a través de la creación, las personas con TCA pueden acceder a constructos intrapsíquicos y a expresar sus sentimientos, más allá de aspectos relacionados con la alimentación. En esa misma revisión también destacan las aportaciones de Shaverien (1994), añadiendo que lo que en un principio son representaciones inconscientes a través de la alimentación, pueden convertirse en representaciones conscientes a través del pro- 
ceso creativo. Es decir, defiende la obra de arte como un nuevo objeto transicional a través del cual se comunica la acción inconsciente. La obra se puede entender como el chivo expiatorio, ya que puede encarnar el caos temido y reflejar el mundo interno (Shaverien, 2000). La imagen, incluso aquella que aparece en las primeras obras de las anoréxicas, permite la posibilidad del desorden contenido, enmarcado dentro del espacio de la imagen. Aquí el caos puede ser colocado de manera segura dentro de los límites del papel, separado del creador (Matto, 2000).

A la hora de trabajar con personas diagnosticadas de TCA, es necesario conocer la situación emocional. Es fundamental ser consciente de que para que se establezca un buen vínculo es necesario estar preparado para la negociación constate, debido a su necesidad de controlar sesiones, espacios y materiales.

Superar la enfermedad supone perder una parte importante de su identidad para encontrarse con algo desconocido. Por ello, incluir un programa de arteterapia dentro del tratamiento hospitalario permite que puedan explorar sus emociones y conductas dentro de un espacio seguro. De este modo, logran desarrollar recursos personales con los que elaborar sus conflictos y descubrir nuevas capacidades creativas, posibilitando con ello una resignificación de su propia imagen que les permite verse capaces de enfrentarse a situaciones desconocidas.

\section{La obra como objeto transicional en el tratamiento de la anorexia}

El objeto transicional (Winnicott, 1971) es un objeto que media entre la madre y el medio ambiente. Objeto real con presencia física, como un oso de peluche o un trozo de tela, al que el niño crea un apego temprano. Gracias a este objeto transitorio, el bebé comienza a ser capaz de mantenerse tranquilo y confiar en la madre en su ausencia.

De acuerdo con Shaverien (1994) la arteterapia ofrece una alternativa; una forma de promulgar y simbolizar los conflictos internos. Del mismo modo que para las pacientes con anorexia, la comida se ha convertido en ese objeto transicional, a través de la arteterapia las obras pueden convertirse en ese osito de peluche que les ayude a resolver los conflictos inconscientes y a externalizar sus conscientes preocupaciones. Los materiales del mismo modo que la comida tienen un aspecto, una presencia física, los cuales el terapeuta ofrece al paciente para su uso y disfrute, del mismo modo que la madre ofrece la comida a su hijo.

El uso de alimentos como objeto transicional podría ser entendido como un desplazamiento inconsciente de una ansiedad o miedo. Si este desplazamiento puede ser canalizado a través de materiales artísticos, la obra como objeto transicional temporal puede facilitar el inicio del movimiento, estado fundido inconsciente donde se activa el pensamiento mágico y la diferenciación. Las emociones dolorosas podrían pasar de actuarse en la alimentación a expresarse en el proceso creativo y depositarse en la obra.

La arteterapia crea un espacio en donde la paciente puede compartir potencialmente el mundo imaginario que por miedo a perder el control nunca permite que aflore. Las anoréxicas no suelen atreverse a soñar por los riegos que pueden ocasionar esos pensamientos. El setting en la arteterapia permite un caos contenido que tiene sus límites marcados en los límites de la obra. La creación de esta imagen protege la zona de transición (Winnicott, 1971); se mantiene el espacio entre le paciente y el 
terapeuta. El mundo imaginario se manifiesta en la imagen, pero no hay una obligación de acceder, la paciente tiene el control de quién quiere que lo vea y quién tiene el derecho a cuestionarlo.

\section{Objetivo}

El objetivo de este trabajo es mostrar cómo la arteterapia permite ampliar la perspectiva de la paciente con trastorno de conducta alimentaria, hacia una conducta más saludable y profundizar en su situación emocional, sin necesidad de vincularse directamente con el trastorno. El cuerpo, elemento fundamental en esta enfermedad, es utilizado en el trabajo plástico como herramienta mediante la cual expresar ideas y percibir sensaciones, permitiendo que la paciente a través de él tome consciencia de la enfermedad, asumiendo sus limitaciones y circunstancias actuales al redescubrir y trabajar la parte sana tras varias décadas de enfermedad.

\section{Pregunta de investigación}

¿Es posible facilitar el acercamiento hacia la parte sana a través del proceso creativo?

\section{Caso de estudio}

Las observaciones que se aportan en este estudio de caso, parten de las sesiones de arteterapia que se han llevado a cabo en un Hospital de Día especializado en anorexia y bulimia. Las sesiones individuales fueron semanales con una duración de una hora, desde noviembre del 2015 a abril del 2016. De las veinte sesiones estudiadas, únicamente la paciente se ausentó en dos ocasiones por motivos médicos.

\subsection{Historial}

¿Qué quiere una anoréxica? Imponerse a su cuerpo. Determinar absolutamente que solo necesite lo que ella decida. Por ejemplo, que no crezca, sobre todo a lo ancho, es decir que no se desarrolle sexualmente. Que su cuerpo no crezca a su aire desobedeciéndole. El caso que en este trabajo se presenta es el de una mujer con anorexia crónica, a la cual llamaré Sandra. Fue derivada para asistir a sesiones de arteterapia al ser una antigua paciente del hospital.

Sandra una mujer en la cuarentena, hija menor de cuatro hermanos de una familia de clase media, sufre un trastorno obsesivo compulsivo y anorexia nerviosa restrictiva que combina con mucho deporte para compensar las calorías que ingiere. Desde la pubertad la comida ocupa el centro de su esfera psíquica, vive por y para la comida, para ingerirla y para quemarla. Estas restricciones alimentarias y el excesivo ejercicio le han generado varias secuelas físicas: osteoporosis, problemas de espalda y anemia crónica entre otras dolencias.

Lleva con la enfermedad cronificada desde hace más de treinta años. Todo comenzó cuando su familia se mudó de casa y Sandra, que tenía por entonces catorce 
años, tuvo que ir a un nuevo instituto. Entonces, perdió a los pocos amigos que tenía, se encontraba muy sola y eso le llevó a tener su primer atracón.

El trastorno de la conducta alimentaria se fue desarrollando poco a poco desde entonces, acentuándose cuando se encontraba estudiando la carrera de Medicina y fue ingresada por primera vez a la edad de veinte años. Sandra afirma que antes de comenzar en la universidad, llevaba muchos años en un estado de tristeza y depresión, debido a que siempre se sentía señalada por sus compañeros, por ser buena estudiante y poco agraciada físicamente; cuando le comentaba a su madre estas preocupaciones, esta soledad, no sentía el cariño de ella.

Los pacientes con TCA tienen una capacidad de mentalización insuficiente debido a que la construcción de su self se ha visto afectada, tras haber desarrollado un vínculo no seguro con su madre en la infancia y sufrir varios problemas relacionales en su pubertad. Esta falta de conocimiento del self, les genera tener poco insight, no simbolizan los conflictos y muchas situaciones traumáticas como un ingreso o un intento de suicido, lo mencionan sin conectar con la emoción, de un modo patológico, se identifican con la enfermedad como parte de su identidad.

Tiene muy pocas amistades, ya que posee escasas habilidades sociales, es incapaz de mentalizar con desconocidos, ya que siempre piensa que la están juzgando y salta a la defensiva con respuestas poco apropiadas. Desde hace más de veinte años, Sandra tiene una relación con un hombre. La relación desde fuera se ve muy sana y ella sonríe cuando habla de su pareja. Es una persona comprensiva que la quiere mucho y la acepta tal y como es.

Sandra, no es capaz de identificar sus propios deseos y sentimientos; y por tanto no es capaz de regular y tomar decisiones por ella misma. Siempre anda indecisa y hace caso de todo aquello que van diciendo las personas que le rodean, ya que su falta de autoestima le hace pensar que los demás tienen siempre razón.

A pesar de vivir a solas con su madre no tiene una buena relación, ya que desde pequeña no se ha sentido querida por ella y en ocasiones la considera culpable de su enfermedad, ya que no la dejó enfrentarse a la vida y la protegió excesivamente. Sandra siempre fue la niña favorita de su padre, se sentía muy querida y protegida por él. Cuando falleció ella contaba con veintiocho años, fue un trago muy duro, se emociona a día de hoy cuando habla de él. Su padre supuso un gran apoyo en su vida, sobretodo porque se sentía desplazada por su madre.

Aunque no logró terminar su último año de Medicina, pudo sacarse el título de auxiliar de enfermería y ha trabajado en varios hospitales; no ha tenido buenas experiencias ya que siempre ha tenido problemas con sus compañeros.

Actualmente su vida se limita a ir a la biblioteca, estudiar inglés, pasar tiempo con su pareja e ir al gimnasio. El deporte desde su adolescencia ha sido su aliado, un refugio donde destacar que le ha servido para sentirse mejor, a la vez que le ha ayudado a controlar su peso.

Intentó en numerosas ocasiones retomar sus estudios de Medicina y sacarse el título de profesora de pilates, pero finamente ante la ansiedad que le genera la presión de ser evaluada, abandona ya que no es capaz de enfrentarse a los pequeños contratiempos diarios. No se permite disfrutar porque siempre anticipa una contrapartida negativa. Por supuesto, este complicado cuadro emocional es compañero inseparable de la tortura que supone la hora de comer. 
Sandra llega a la terapia muy escéptica, tiene un gran bloqueo emocional y muy baja autoestima. Además, el psiquiatra le ha cambiado la medicación esta semana y aún está adaptándose, le cuesta mucho levantarse por las mañanas.

\subsection{Sesiones de arteterapia más relevantes en el proceso}

\subsubsection{Sesiones iniciales: dibujando biorritmos}

Holly Matto (2000) describe como las pacientes anoréxicas a diferencia de las bulímicas que tienden a derrochar material, inician el proceso terapéutico, de la misma forma en que se relacionan con la comida, de un modo extremadamente selectivo, observando el material, tomándose su tiempo, controlando en todo momento la situación. Es muy común que se decanten por un simple lápiz. Mientras las bulímicas ocuparan todo el espacio del papel realizando obras muy densas que tardan en secar; las anoréxicas se aproximan a la obra de un modo más tímido y pausado, usando poco material, como si cada vez que hicieran una tímida marca en el papel estuvieran consumiendo un bocado de comida. Tendiendo a realizar imágenes aisladas, con mucho aire; imágenes que respiran, que flotan y se pierden en el papel.

$Y$ es que realmente cuando coloqué los materiales en nuestra primera sesión, es como si estuviera preparando la mesa para Sandra: los platos, las servilletas y el vaso de agua; y finalmente la comida para que ella pudiera posteriormente elegir qué consumir. Se aproximó a los materiales de modo tímido, como si estuviera saboreando aquello que tenía entre manos. El papel seleccionado fue un folio de color blanco, el cual se le veía que se la hacía inmenso, el miedo al lienzo en blanco, al vacío, se percibía en su cara. Aunque no utilizó la goma de borrar, empezó a trabajar muy despacio, describiendo con diferentes pinturas como era para ella un día normal, dibujando un biorritmo de su estado anímico, distinguiendo los peores momentos del día con colores fríos, reservando el negro para los momentos más dramáticos, cuando la ansiedad le superaba y entonces tomaba una pastilla para quedarse dormida. Los colores cálidos fueron utilizados para representar los momentos de mayor tranquilidad y bienestar (Figura 1).

Me sorprendió que, en esta primera sesión, Sandra tomara las pinturas de cera en vez de hacer uso del lápiz que aporta mayor control. Su gesto lo interprete como un buen indicio de predisposición a atreverse, al cambio.

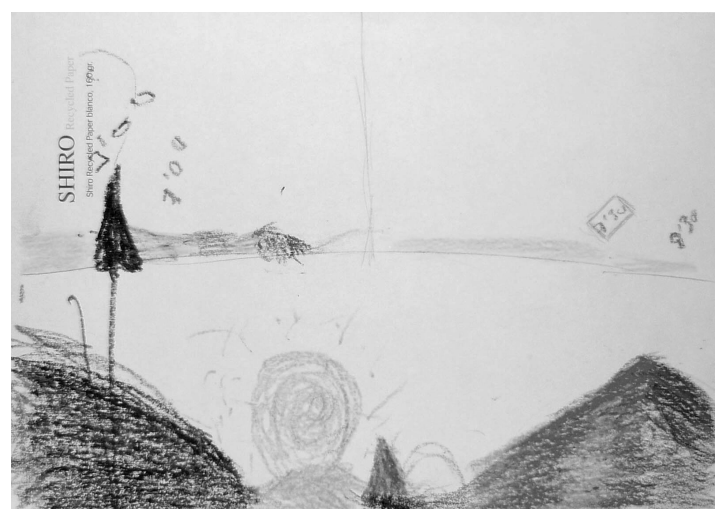

F1. Sin título. Obra realizada en la primera sesión. 
El miedo a perder el control puede en algunos casos ser equivalente al temor de perder toda su existencia. Por lo tanto, comenzar a pintar puede representar un paso audaz hacia lo desconocido, y este es el principal motivo por el que este colectivo en ocasiones se niega a participar en este tipo de terapias artísticas (Murphy, 2000). Pero Sandra, aunque no sabía muy bien en esta primera sesión que era exactamente arteterapia, se mostró muy colaboradora y participativa.

La pérdida de control y el miedo a los imprevistos salieron a la luz en nuestra segunda sesión, cuando ella muy nerviosa me llamó por teléfono siete horas antes de nuestra cita, para comunicarme que quería dejar las sesiones de arteterapia ya que había sufrido varios imprevistos esa semana; se encontraba agobiada y con mucha ansiedad. Finalmente acudió puntual y tranquila a la segunda sesión; comunicándome que se había agobiado, ya que en la mañana al ir a su consulta médica, el psiquiatra le había informado que tenía el hierro muy bajo y que sería conveniente que ingresara. Este comentario le cogió por sorpresa, y por ello, decidió llamarme y abandonar la actividad.

Ese día mientras me contaba lo sucedido, continuó dibujando biorritmos del mismo modo que en la primera sesión, utilizando colores y formas desde la parte inferior izquierda de la hoja hacia la parte inferior derecha. En esta ocasión la tuve que llevar más a la obra ya que andaba con más ansiedad. El título que puso a la obra resumió perfectamente lo que me estaba contando "imprevistos continuados" (Figura 2). Era un buen título para esta segunda sesión en donde Sandra, de un modo muy sutil, fue dejando ver lo que serían las siguientes sesiones, lo que sería estar pendiente todos los lunes por la mañana del teléfono para saber si abandonaría la terapia o no. Ella era ese ser agonizante, ese iceberg que aunque ahora estaba a flote, nunca sabes cuando los imprevistos van a conseguir que se derrita.

Aunque resultó ser una sesión difícil, ya que al inicio no sabía cómo Sandra iba a reaccionar. Me alivió apreciar su colaboración y sentir que ambas salíamos de la sesión mejor de lo que habíamos entrado.

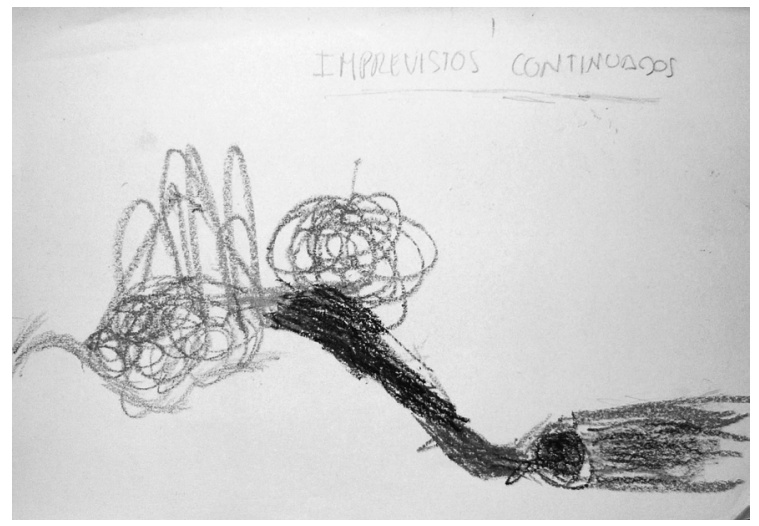

F2. Imprevistos continuados. Obra realizada en la segunda sesión.

Sandra no tenía mucha destreza con los materiales y lo sabía, es por ello que estuvo repitiendo el mismo tipo de dibujo hasta la sexta sesión. Aunque en ocasiones sentía que tenía que dirigirla para que cambiara el modo en el que se enfrentara al lienzo blanco, opté por esperar a ver lo que sucedía. 
Sandra no estaba pasando por una etapa muy estable, se encontraba muy angustiada y muy deprimida, incluso me planteó en varias ocasiones que quería ingresar en el hospital voluntariamente. Sus obras se inclinaban hacia la repetición, sesión tras sesión repetía esos biorritmos con mayor o menor intensidad, no se quería alejar de aquello que controlaba por el temor que le suscitaba lo desconocido. Como bien dice Winnicott (1971) el terapeuta debe saber esperar para empezar a jugar juntos. Así que opté por apoyarla y acompañarla en el proceso creativo ya que crear el vínculo era el objetivo principal que tenía con ella en ese tiempo. En todo momento evité realizar juicios a su obra que no fueran sobre temas formales, ya que era consciente de su susceptibilidad a los comentarios.

Mi nivel de intervención con Sandra empezó a definirse tras las primeras cuatro sesiones. Veía conveniente que utilizara ese espacio para la discusión de problemas actuales. Debido al tiempo que nos quedaba juntas, no podría desarrollar una intervención profunda ya que pensé que ambas no estábamos preparadas para abrir la herida y cerrarla en tan pocas sesiones. Así pues, poco a poco fui vislumbrando que mi objetivo principal con Sandra, además de crear ese vínculo sano, era acompañarla en el aquí y en el ahora trabajando aquello que me trajera sesión tras sesión, de un modo creativo y nuevo para ella, gracias a la libertad que le suponía ese espacio.

\subsubsection{Sesión sexta: aparece la imagen encarnada}

Algo nuevo sucedió en la sesión sexta. Entró en la sala llorando, diciendo que no podía vivir más en esa casa, que no valía para nada, que en su vida solo había estudiado y que ahora no tenía nada, ni carrera ni trabajo. Se encontraba desconsolada, abatida y tremendamente triste. Al verla tan angustiada, le ofrecí el barro para que se relajara y se tranquilizara.

En un estado intermedio del tratamiento con anoréxicas Mari Flaming (2000) nos aconseja fomentar la expresión con el uso de nuevos materiales como oleos, acrílicos o arcilla para promover la auto-investigación. Este tipo de materiales, debido a sus cualidades físicas más similares a los fluidos corporales, invitan a la regresión. Sandra ese día debido a todo aquello que traía y en contacto con el material, el barro, conectó con la emoción y tuvimos una sesión muy intensa. Me comunicó muy emocionada los inicios de la enfermedad cuando era una adolescente, el miedo que tiene a los cambios y la tristeza que le causó la pérdida de su padre. Mientras masajeaba el barro se iba tranquilizando, entonces fue cuando verbalizó que se sentía mala persona por odiar a su hermana y a su madre. Ella no se encuentra feliz en esa casa, ya que no la siente suya. Sin parar de llorar terminó la sesión contándome como el año pasado había sufrido dos abortos naturales y cómo tal suceso, tanto a ella como a su pareja les había causado un terrible dolor. Pero lo más doloroso fue cuando su madre y hermana no la apoyaron ni la consolaron por dicha pérdida. La obra de esa sesión, esa obra con aspecto orgánica, se convirtió en la primera obra encarnada, en ese chivo expiatorio, que era reflejo de su mundo interior (Figura 3). Los biorritmos de las primeras sesiones, esa imagen diagramática, dio paso a este tipo de imagen extrañamente confortable que absorbía toda la energía que se había vivido en la sesión. En ese trozo de arcilla Sandra había fundido y encerrado por primera vez sus sentimientos.

Esta sesión me sirvió como testigo para saber que el vínculo era bueno, al demostrarme con sus confidencias que sentía ese espacio como un lugar seguro, donde na- 
die juzgaba y donde podía volcar toda su ansiedad y preocupaciones. A pesar de ello, en ocasiones me resultaba difícil discernir su angustia de la mía. La contratransferencia se hizo presente, cuando me preguntaba buscando soluciones y yo, por miedo a que se "rompiera", evitaba el silencio intentando dar respuesta a su intranquilidad y a la mía, aun sabiendo que no era mi labor. Este tema lo llevé a la supervisión, ya que no sabía cómo atajar mi propia ansiedad frente a sus preguntas. Hacerle ver el problema desde otro punto de vista, dándole pistas pero nunca consejos, me ayudó a mantenerme con un pie fuera de la sesión y a no identificarme con sus problemas, ya que la contratransferencia era tal, que muchas veces me asustaba de mis propias emociones cuando me encontraba fuera de sesión.

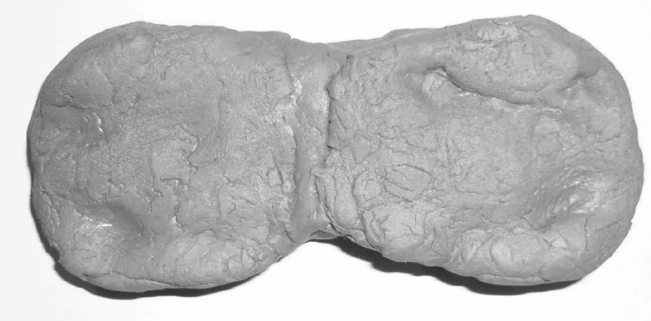

F3. Sin título. Primera obra encarnada realizada en la sexta sesión.

\subsubsection{Sesión octava: aparece el paisaje}

Después de más de dos meses juntas y tras las Fiestas de Navidad, Sandra llegó a la sesión muy alegre y le propuse que usara las pinturas acrílicas ya que durante las sesiones anteriores me había preguntado con curiosidad, pero nunca se había atrevido a cogerlas. Se la percibe con más energía que en sesiones anteriores, parece increíble que sea la misma persona que hace tres semanas quería ingresar en el hospital voluntariamente. Por primera vez en sesión, se propone hacer un dibujo de un paisaje y piensa en algo que le hace feliz. Sonriendo y disfrutando del nuevo material, comienza a pintar un mar con muchos colores, utilizando los dedos.

Las anoréxicas no suelen tener fantasías, su pensamiento mágico esta mermado, ya que dejar volar su imaginación supone una perdida del control. Lanza (2011) argumenta como "la posibilidad de conectar el mundo de la fantasía y la emoción con el comportamiento, tanto en uno mismo como en los demás, favorece la riqueza y profundidad del vínculo con el otro, tornando significativo el intercambio interpersonal". Hasta esta octava sesión Sandra no se permitió el lujo de soñar despierta, ni de pintar un paisaje que la hiciera feliz. A través de la imagen en esta sesión, Sandra verbalizó sus ganas por la llegada del verano para ver el mar y volver a sentir esa sensación tan agradable para ella, que es dejarse secar al sol tras haberse dado un buen baño. Este recuerdo, esa imagen que ella fue dibujando mientras hablaba de 
esas buenas sensaciones, dibujó en ella una sonrisa y un brillo especial en su mirada que hasta el día de hoy no había podido apreciar, ya que hasta esa fecha no se había permitido dejar volar su imaginación y recrearse en aquellas sensaciones que la hacían feliz. En esa sesión, por primera vez desde el inicio de la terapia, no me trajo la enfermedad ni las angustias; hablamos de nuevos temas, de sus inquietudes, de sus deseos y de sus planes de futuro. Se la veía contenta con su obra, orgullosa. La tituló "alegría "y fue también ese día la primera vez que quiso colocar fecha en la obra (Figura 4). A la hora de despedirnos yo siempre la agradecía que hubiera venido, ya que sabía que para ella suponía un esfuerzo tanto mental como físico. Ella esta vez se despidió diciéndome: "Gracias a ti cielo". El tono cariñoso de su despedida me cogió por sorpresa, pero lo encajé con ilusión ya que suponía una prueba más de la fortaleza del vínculo que habíamos construido.

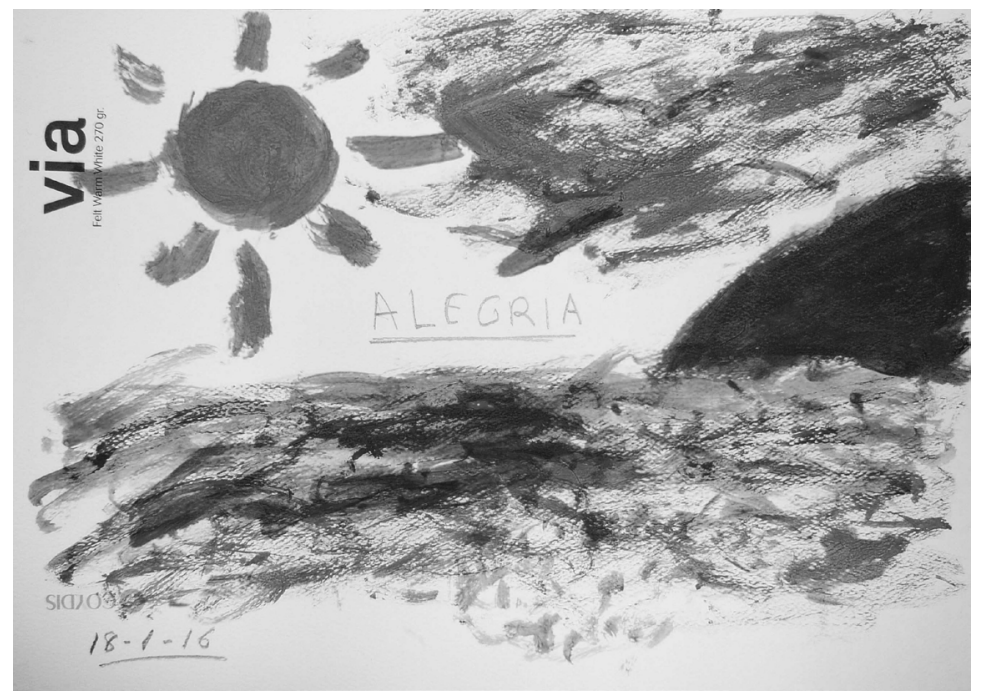

F4. Alegría. Obra realizada en la octava sesión.

Aunque había usado un material nuevo la ansiedad no la invadió, al contrario, la tranquilizó y supo disfrutar del proceso creativo. Y del mismo modo que la madre suficientemente buena, como terapeuta tomé el riesgo de ver que sucedía si utilizaba un nuevo material. Mi función no era únicamente proveer el alimento, el material a Sandra, también era proteger y contener el espacio para que fuera seguro. En esta sesión comencé a entender que el objetivo principal que debía tener con ella era trabajar la parte sana, esa parte que se encontraba tremendamente oculta debido al gran tamaño que ocupaba la patología al llevar tanto tiempo instaurada en su self, formando parte de su identidad. En esta sesión Sandra aceptó perfectamente el no saber y es interesante como en las sesiones posteriores se dejó llevar, olvidando el control, comenzando a experimentar y jugar con los materiales. La creación implica poner en juego con mayor o menor intensidad una serie de habilidades o aprendizajes. Y este juego y este disfrute por la realización de la obra comenzó a hacerse visible cuando definidamente el iceberg, el ser agonizante, que todos los lunes en la mañana se cuestionaba su existencia, decidió tomar consciencia de su realidad y mirar hacia delante. 


\subsubsection{Sesión undécima: comenzamos a trabajar con la parte sana}

Me había dejado ese lunes en la mañana el teléfono en casa, cuando al llegar, vi que tenía tres llamadas perdidas y un WhtatsApp de Sandra comunicándome que quería abandonar la terapia definitivamente, ya que estaba cansada de recordarse a sí misma que se encontraba enferma. En el mensaje de WhatsApp me redactaba claramente cómo ya era hora de comportarse como una adulta y no como una adolescente, buscando siempre excusas para no afrontar la vida, escudándose en la enfermedad y la necesidad de terapia. Este tipo de pensamientos fueron influenciados por su hermana. La psicóloga clínica del centro se puso en contacto con ella y le comunicó que para ella tomar un compromiso ya era en sí mismo algo terapéutico, ya que ante cualquier dificultad no podía abandonarlo todo. Finalmente me llamó para comunicarme que aunque llegaría quince minutos tarde, continuaría con la arteterapia ya que había tomado un compromiso conmigo.

A pesar de lo sucedido, se la vio que entraba en sesión con energía, me pidió un pincel, era la primera vez que no utilizaba los dedos y se dispuso a pintar con pintura acrílica. Se la veía que había tomado la iniciativa de disfrutar y aprovechar ese espacio sin hacer caso a los comentarios de su familia. Comenzó a dibujar la obra (Figura.5) con gran intensidad comentándome que lo que estaba representando tenía relación con lo difícil que era para ella el día a día.

Colocó una serie de flechas negras muy dramáticas que verbalizó que eran aquellas personas que la rodeaban y con sus comentarios le hacían la vida más complicada aún, como si para ella no fuera sencillo levantarse, preparar la comida y sacar energías para ir al gimnasio y a la biblioteca.

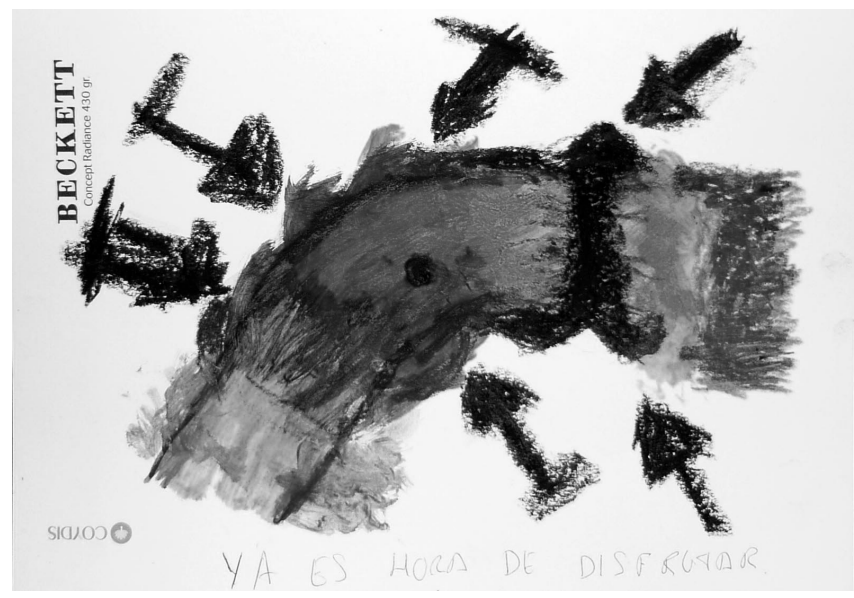

F5. Ya es hora de disfrutar. Obra realizada en la undécima sesión.

Ese punto diminuto negro en medio de la obra, es ella, la cual siempre anda en duda ya que esas flechas siempre la alteran y la confunden. Para mostrarme su compromiso, increíblemente a pesar de lo dicho esa mañana por teléfono, trajo unas pinturas al agua que tenía en casa para hacer uso de ellas en las sesiones sucesivas. Sentí este gesto como algo muy bueno para el vínculo terapéutico. Al preguntarle por el título de la obra no se lo pensó mucho, lo tenía muy claro "Ya es hora de disfrutar". Y es justamente esto lo que hizo en las sucesivas sesiones. Ahora ella necesita 
ser feliz, por fin. Ha tenido una vida complicada, pero ahora la pulsión de vida la ha invadido. Sandra ha entendido que el espacio que hemos construido no es un sitio en donde hablar únicamente de problemas, podemos hablar de lo que ella quiera y traiga, y ahora lo que ella necesita es ver que Sandra es mucho más que una mujer anoréxica, que en su vida hay muchas más cosas, que ella puede compartir conmigo y con los demás.

\subsubsection{Sesiones finales: juego y experimentación}

En las sesiones siguientes comenzó a disfrutar del proceso creativo, comenzó a jugar. La creación implica juego, y así es como ella se tomó ese espacio, una vez que decidió no hablar de la enfermedad y centrarse en otra parte de su vida. La terapia se centró en una psicoterapia positiva entendiendo la creatividad como una forma de cambio. Ella en varias ocasiones a lo largo de este tiempo juntas, me devolvió que gracias a esas sesiones, se había dado cuenta de todas aquellas cosas buenas que tenía en su vida y nunca había valorado.

Sandra, a partir de esa sesión undécima, a partir de esa sesión clave, venía a la sesión con una idea en la cabeza. La sesión no solo se limitaba a los sesenta minutos en los que yo estaba presente, la sesión estaba en su cabeza toda la semana. En la sesión decimocuarta, se aventuró por un papel más grande, ese primer gesto del primer día en su cara, al ver el vacío del papel en blanco, se había disipado. Ahora dibujaba con intensidad, mezclando colores, teniendo día a día más destreza con los materiales, dominando el material. La confianza hizo que me sugiriera que la trajera música ya que quería trabajar más la parte emocional y dejar a un lado su parte racional. Ahora ya no dibujaba biorritmos con la mano tensa, ahora se dejaba llevar por el pincel, permitiéndose el fallo. Dibujando paisajes, sensaciones y deseos todo ellos con vivos colores, en donde predominaban los colores cálidos, aquellos que ella relaciona con el bienestar; imágenes encarnadas (Figura 6).

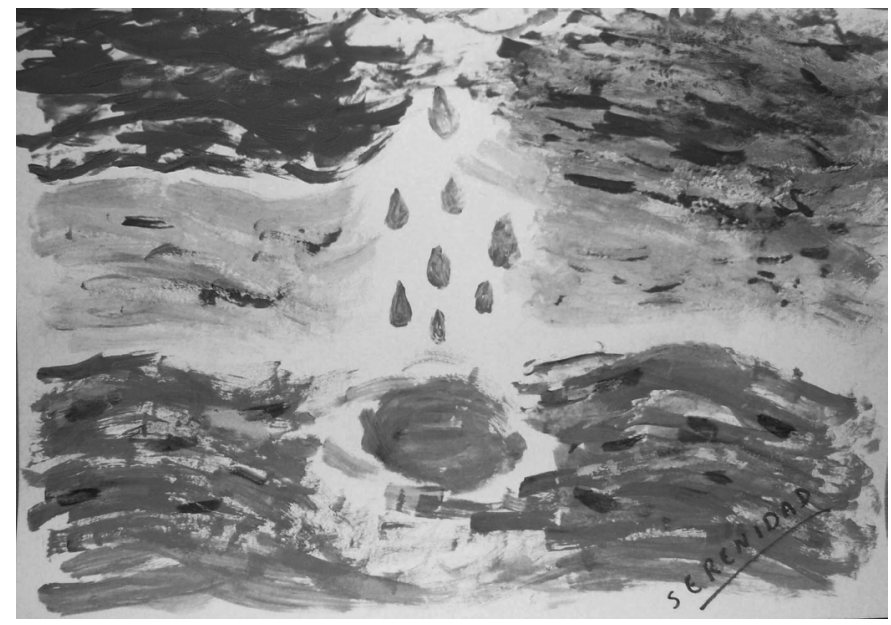

F6. Serenidad. Obra realizada en la decimoséptima sesión.

Ahora en esos paisajes, Sandra se sentía capaz de plasmar y comunicar aquello que quería expresar y eso aumentó su autoestima a pesar de no tener habilidades 
para el dibujo. En esta frase, Ramos (2001) resume claramente las nuevas sensaciones que comenzó a experimentar. "Cuando el motivo interno (conglomerado de sentimientos que impulsa a crear) y el mundo externo (la obra forma) coinciden, se produce una catarsis que se convierte en un sentimiento de placeres estéticos acompañado por insight (darse cuenta). Descubrir lo que andamos buscando, plasmarlo y sacarlo reduce por tanto la ansiedad".

\section{Conclusiones}

Al evaluar la evolución de Sandra en el proceso artístico, tomando en cuenta las notas escritas tras las sesiones y analizando las obras, se identificaron tres aspectos fundamentales que el trabajo en arteterapia le ha ofrecido.

\subsection{El proceso de creación como entrenamiento para el cambio}

A Sandra, el programa de arteterapia le ha permitido una nueva experiencia de vinculación, donde la obra ha sido testigo de este nuevo vínculo, tan útil para ella en un futuro, ya que le ha servido como entrenamiento a la hora de relacionarse con personas desconocidas desde una perspectiva sana, lejos del juicio previo del que ella partía. Comprometerse a este tipo de actividad y no abandonar, resultó ser altamente terapéutico en su caso, ya que siempre tiende a no finalizar todo aquello que inicia. Demostrarse a sí misma que es capaz de terminar algo y asumir responsabilidad le ayudará en un futuro cuando se enfrente en situaciones similares.

Gracias al setting establecido, Sandra encontró un espacio donde pudo reflexionar acerca de sus mecanismos de actuación y analizar por si misma pautas de trabajo y de conducta, tomando conciencia de ello desde una perspectiva experiencial y metafórica. A través de las sesiones, se favoreció un proceso creativo en el que Sandra pudo identificar algunas de sus conductas patológicas como la necesidad de control, el miedo a ser juzgada, la necesidad de agradar, la desconfianza interpersonal, la identificación de emociones o la excesiva preocupación por lo que piensen los demás. Ello le permitió ir hacia la experimentación de probar, imaginar y tomar parte de cosas nuevas.

\subsection{La vinculación de la autora con su obra}

Al analizar el desarrollo del proceso creativo, se puede comprender cómo en un principio en Sandra se destaca la inseguridad que presentaba y el rechazo que sentía hacia sus propias creaciones. A medida que aumenta la confianza en sí misma y comprende mejor el espacio, comienzan a surgir motivos pictóricos más profundos y significativos relacionados con la pulsión de vida, por lo que la producción plástica se convierte en un objeto mediante el que redescubrir esa parte sana que tan oculta se encuentra por el gran espacio que ocupa la enfermedad en su vida.

\subsection{Una nueva visión de sí misma}

A través del trabajo creativo, Sandra desarrolló mayor flexibilidad, intuición y capacidad de improvisación, adquiriendo un mayor equilibrio entre control e impulsi- 
vidad. Por otro lado, la exploración de las dinámicas artísticas le ayudó a disminuir su ansiedad ante lo desconocido, a reducir la obsesión por la perfección para poder desarrollar un discurso personal y elaborar un proceso de trabajo con el que disfrutar, superando la apatía.

\section{Bibliografia}

Calvo, R. (2002). Anorexia y bulimia. Guía para padres, educadores y terapeutas. Barcelona: Editorial Planeta.

Eichenbaum, L. y Orbach, S. (1983). What do Women Want. London: Penguin.

Flaming, M. (2000). Art therapy and eating disorders. En S.R. Makin (Ed.). More than just a meal: The art of eating disorders (pp. 42-67). London and Philadelphia: Jessica Kinsgley Publishers.

Gilroy, A. (2012). The evidence base for art therapy with adults. Eating disorders. Art therapy, research and evidence-based practice (pp. 126-129). London: Sage.

Henzell, J. (1997). Art in Treatment: Transatlantic Dialogue. London: Charles C Thomas.

Kleim, J. P. (2006). La creación como proceso de transformación. Arteterapia. Papeles de arteterapia y educación artística para la inclusión social, 1, 11-18.

Lanza, G. (2011). La mentalización, su arquitectura, funciones y aplicaciones prácticas. http://www.aperturas.org/articulo.php?articulo=722.

López, M. y Martínez, N. (2006). Arteterapia. Conocimiento interior a través de la expresión artística. Madrid: Tutor.

Matto, H. (2000). Art therapy and eating disorders. En S.R.Makin ( Ed.). More than just a meal: The art of eating disorders (pp. 42-67). London and Philadelphia: Jessica Kinsgley Publishers.

Menéndez, I. (2013). Madre-hija, conflicto (también) está en el plato. http://www.mujerhoy. $\mathrm{com} / \mathrm{psico}-\mathrm{sexo} / \mathrm{madrehija-conflicto-tambien-esta-750346102013.html.}$

Puertas, P. (2002). El grupo de anoréxicas: Una alternativa nutritiva. Bilbao:

Ediciones Altxa.

Ramos, C. (2001). Between the inside and the outside, an approach to the creative process in the art making. Images do transformaçao, 2.

Shaverien, J. (1994). The picture as transactional object in the treatment of anorexia.

En D. Dotter. Arts therapies and clients with eating disorders (pp. 31-47). United Kingdom: Jessica Kinsgley Publishers.

Shaverien, J. (2000). Art therapy and eating disorders. En S.R. Makin (Ed.). More than just a meal: The art of eating disorders (pp. 42-67). London and Philadelphia: Jessica Kinsgley Publishers.

Winnicott, D. (1971). Realidad y Juego. Barcelona: Gedisa.

\section{Agradecimientos}

Contenido basado en las prácticas de formación de la Universidad Pompeu Fabra. Sibylle Cseri llevó la supervisión. 